Research Article

\title{
Efficacy Analysis of Thickness and Camber Size of Cross Section of the Stator on Hydrodynamic Parameters in Linear Jet Propulsion System
}

\author{
Negin Donyavizadeh (iD) and Parviz Ghadimi if \\ Department of Marine Technology, Amirkabir University of Technology, Tehran, Iran \\ Correspondence should be addressed to Parviz Ghadimi; pghadimi@aut.ac.ir
}

Received 14 May 2020; Accepted 21 July 2020; Published 12 August 2020

Academic Editor: Jefferson L. M. A. Gomes

Copyright (c) 2020 Negin Donyavizadeh and Parviz Ghadimi. This is an open access article distributed under the Creative Commons Attribution License, which permits unrestricted use, distribution, and reproduction in any medium, provided the original work is properly cited.

\begin{abstract}
The linear jet propulsion system, unlike pump-jets which are widely used in underwater bodies, is installed inside a tunnel under the vessel and can be used for high-speed crafts, tugs, and service boats. However, this system has not received adequate attention by researchers, which is the subject of the current study. In the present paper, hydrodynamic performance of the linear jet propulsion system is numerically investigated. Accordingly, the Ansys-CFX software is utilized and RANS equations are solved using the SST turbulent model. The results of the proposed numerical model, in the form of thrust and torque coefficient as well as efficiency, are compared with available experimental data for a ducted propeller, and good compliance is achieved. Considering the importance of stator cross section on the performance of the linear jet propulsion system, the influence of thickness and camber size of the stator on linear jet propulsion systems are examined. Based on the numerical findings, it is determined that at constant advance ratio, with increasing thickness of stator, the efficiency increases. It is also observed that as the span length increases, the maximum and minimum of the pressure coefficient increase for different thicknesses. Furthermore, it is seen that positive and negative pressure coefficients decrease with an increase in foil thickness.
\end{abstract}

\section{Introduction}

One of the main components in a vessel is its propulsion system. The main function of the propulsion system is to produce the thrust required to move the vessel. One type of this system is linear jet propulsion system which is appropriate for a speed range between conventional propellers and water jets. Conventional propellers tend to produce cavitation at high ship speeds. This causes losses in efficiency and damages the propeller. Water jets deliver high thrust at high speeds, but their efficiency is not competitive at lower speeds [1]. This system, like pump-jet, consists of three main parts: duct, rotor, and stator. The main difference between linear jet and pump-jet is their application. Pump-jets are widely used in underwater bodies, but linear jet is installed inside a tunnel under the vessel and it can be used for high speed crafts, tugs, and service boats. In linear jet system, the stators can be installed on the upstream (preswirl) or downstream (postswirl) of the rotor, which can reduce the rotational losses which occur downstream of a rotor, thereby improving the efficiency of propulsion system [2]. Because of the interaction between the stator and the rotor and complex flow around the rotor in linear jet propulsion system, fewer studies are devoted to linear jet than the conventional propulsion system. In 1991, Hughes [3, 4] placed a stator upstream of the rotor to examine the hydrodynamics characteristic of ducted propeller with preswirl stator. In that study, a potential-based panel method for the duct coupled with the lifting surface method for the rotor and stators was presented. A few years later, for the first time, Jürgens and Bohm [5] introduced a propulsion system for fast ships called a linear jet propulsion system. In 2001, Ivanell [6] investigated a CFD model of the pump-jet propulsion system on a torpedo. He used the experimental result of 
wind tunnel to verify the accuracy of the numerical simulation results. After that, Park et al. [7] solved 3D incompressible RANS equations to analyze a ducted marine propulsor with rotor stator interaction. The single-stage ducted marine propulsor hydrodynamic coefficients and propulsive efficiency were also obtained. A year later, Jürgens and Heinke [8], based on their previous studies [5], presented a complete design with details of the linear jet propulsion system at the annual meeting of STG at Hamburg in November 2006. Since linear jet propulsion system consists of three different parts, change in each of them has a great impact on the hydrodynamic parameters. Therefore, hydrodynamic study of each of them is very important. In 2007, Naujoks et al. [1,9] introduced a method for automatic optimization of a linear jet. In this way, the optimization was first limited to the propeller blade to determine good parameterizations for the optimization method. Finally, they were able to find a competitive linear jet geometry by using an automatic optimization technique with geometry generation tools and hydrodynamic simulation tools. In 2009, Kim [10] conducted numerical simulation of the pump-jet using the Open FOAM software and examined the turbulence flow around a pump-jet. Suryanarayana et al. [11, 12] also performed experiments on a symmetrical body with a pump-jet propulsion system. They measured the thrust force generated by each of the rotor and stator sections of this system in different advance ratios. Furthermore, the torque needed to move the rotor was assessed. Based on their tests, it was observed that propulsion system of the pump-jet has a wider range of performance than the ducted propeller. However, the efficiency of the pump-jet does not exceed $40 \%$. Sorbello [13] showed that linear jet system can increase the Bullard force by about 50\% without increasing the required engine power. In total, this system can be used for vessels between 20 and 60 meters in length. Also, the range of use of this system in terms of speed is between 25 and 40 knots. In 2013, Rao et al. [2] analyzed theoretically the frequency characteristics of unsteady forces arising from the hydrodynamic interaction between the rotor and stators for a ducted propeller with preswirl stators. Furthermore, the hydrodynamic performance of pump-jet propulsor is based on the Reynolds Averaged Navier-Stokes (RANS) computational fluid dynamics (CFD) method using structured grid; SST k- $\omega$ turbulence model was determined by Pan et al. $[14,15]$ and Lu et al. [16]. One year later, in 2017, MotallebiNejad et al. [17] conducted numerical analysis of the pumpjet system using the periodic domain. For validation purposes, they placed a Kaplan 4-70 propeller, produced by PropCad, into an A-19 duct and analyzed it with Ansys-CFX software. Shirazi et al. [18] in 2019 also simulated fluid flow in a full-scale pump-jet using the periodic computational domain and conducted several experiments. Results indicated that stator and duct profiles should be designed very thoughtfully for avoiding the consumption of rotor thrust. Li et al. [19] also performed numerical calculations of fluid flow in a pump-jet with the focus on the mutual interference between the rotor and stator. They discussed the unsteady effects on PJP performance with a comparative study of steady and unsteady flow and analyzed the exciting forces of rotor and stator.

In the present study, considering the importance of stator cross section on the performance of the linear jet propulsion system and the lack of any data in the field of linear jet propulsion system, the effect of thickness and camber size of the stator on linear jet propulsion system are examined. To accomplish this task, ANSYS-CFX software is used to perform numerical simulations. RANS equations are solved using SST turbulent model. First, a ducted propeller system is selected for validation study and numerical results are compared against available experimental data. Subsequently, geometry is produced for a linear jet system and simulated numerically, and different types of NACAxxxx are examined. These simulations are conducted for four advance ratios. Results are expressed in terms of thrust and torque at different advance ratios. Ultimately, the effects of thickness and camber size of the stator on pressure coefficient around the stator are assessed.

\section{Numerical Model}

2.1. Governing Equation. In this study, the fluid is considered incompressible and flow is assumed to be steady. The Reynolds-Averaged Navier-Stokes equation for incompressible Newtonian fluid solved in the current study is given as [17]

$$
\begin{gathered}
\frac{\partial u_{i}}{\partial x_{i}}= \\
\frac{\partial}{\partial t}\left(\rho u_{i}\right)+\frac{\partial}{\partial x_{j}}\left(\rho u_{i} u_{i}\right)=-\frac{\partial P}{\partial x_{i}}+\frac{\partial}{\partial x_{j}}\left[\mu \frac{\partial u_{i}}{\partial x_{j}}-\rho u_{i}^{\prime} u_{j}^{\prime}\right]+f_{i}
\end{gathered}
$$

where $-\rho u_{i}^{\prime} u_{j}^{\prime}$ represents Reynolds stresses. Reynolds stresses in (2) are modeled as follows:

$$
-\rho u_{i}^{\prime} u_{j}^{\prime}=\mu_{t}\left(\frac{\partial u_{i}}{\partial x_{j}}+\frac{\partial u_{j}}{\partial x_{i}}\right)-\frac{2}{3}\left(\rho k+\mu_{t} \frac{\partial u_{k}}{\partial x_{k}}\right) \delta_{i j} .
$$

In this study, the two-equation Shear-Stress Transport (SST) $k$ - $\omega$ turbulence model is used for modeling turbulent viscosity.

2.2. Hydrodynamic Coefficients. For computing and defining the thrust and torque of propeller, nondimensional coefficients are used such as advance coefficient $(J)$, thrust coefficient $\left(K_{T}\right)$, torque coefficient $\left(K_{Q}\right)$, and efficiency $\left(\eta_{O}\right)$ which can be seen in (4) to (7):

$$
J=\frac{V_{A}}{n \cdot D}
$$

Here, $V_{A}$ is advance velocity of the water into the propeller: 
TABle 1: Geometric specifications for propeller ka4.70 with duct 19A [20].

\begin{tabular}{lccccccc}
\hline Duct $(\mathrm{A})$ & Type of duct & $\begin{array}{c}\text { Propeller section } \\
\text { series }\end{array}$ & $\begin{array}{c}\text { Number of } \\
\text { blades }\end{array}$ & $\begin{array}{c}\text { Propeller } \\
\text { diameter }\end{array}$ & $\begin{array}{c}\mathrm{P} / \mathrm{D}_{R} \\
\text { ratio }\end{array}$ & $\begin{array}{c}\text { Expanded area } \\
\text { ratio }\end{array}$ & $\begin{array}{c}\text { Hub diameter } \\
\text { ratio }\end{array}$ \\
\hline 19 & Accelerating & Kaplan & 4 & 0.2 & 1 & 0.7 & 0.2 \\
\hline
\end{tabular}

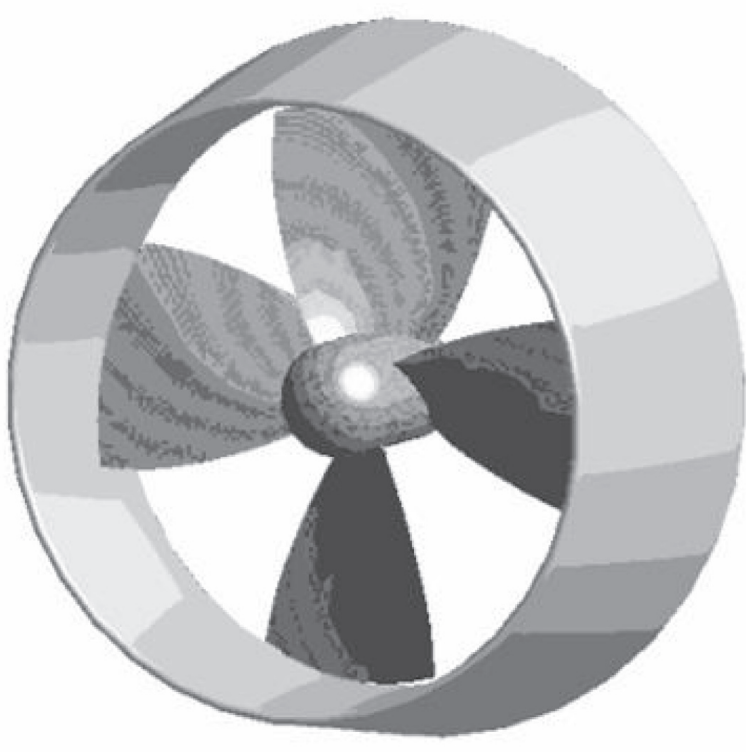

Figure 1: Three-dimensional model of propeller ka4.70, $\mathrm{P} / \mathrm{D}=1$ with duct 19A.

$$
\begin{aligned}
& K_{T}=\frac{T}{\rho \cdot n^{2} \cdot D^{4}}, \\
& K_{Q}=\frac{Q}{\rho \cdot n^{2} \cdot D^{5}} .
\end{aligned}
$$

Equation (7) is used to calculate the propeller efficiency in open water condition:

$$
\eta_{o}=\frac{J}{2 \pi} \frac{K_{T}}{K_{q}}
$$

where $\rho$ is the fluid density around the propeller, $n$ is the rotational speed of the propeller, and $D$ is the diameter of the propeller.

\section{Validation of the Solver}

3.1. Computational Model Setup. In this part of the paper, for verifying the numerical solution, the experimental results [20] available for a ducted propeller are used. For this purpose, a ducted propeller is used as a simplified case of a linear jet system, and its specifications are given in Table 1 . The three-dimensional model of the ducted propeller with $\mathrm{P} / \mathrm{D}=1$ is shown in Figure 1 .

The computational domain is considered as two cylinders (Figure 2). One of them is located around the propeller

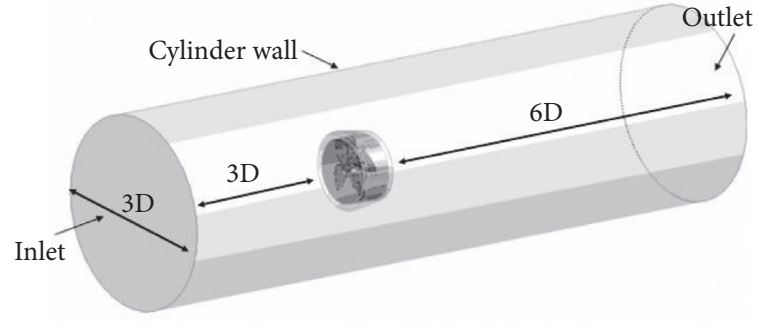

FIgURE 2: Dimensions of the computational domain with determination of the boundary conditions.

TABLe 2: Boundary conditions.

\begin{tabular}{lc}
\hline Boundary & Type of condition \\
\hline Inlet & Velocity inlet \\
Outlet & Pressure gradient \\
Propeller and hub & No slip wall \\
Duct & No slip wall \\
Cylindrical wall & Free slip wall \\
\hline
\end{tabular}

and inside the larger cylinder. This is for the convenience of modeling the rotation of the propeller.

To perform numerical calculations, the initial and boundary conditions of the problem must be determined in Table 2.

The cylindrical walls over which the boundary condition of the free-slip wall is applied are illustrated in Figure 2. At the beginning of the computational domain, the input boundary condition is considered to enter the flow with a constant speed $(4 \mathrm{~m} / \mathrm{s})$ toward the propeller, as shown in Table 2. Also, to establish the mass conservation equation at the end of the computational domain, zero pressure gradient boundary condition is applied. However, the propeller and shaft are placed inside a rotating cylinder, in order to apply a moving mesh.

3.2. Grid Convergence Study. For generating mesh inside the computational domain, Ansys-ICEM software is used. The grid is considered unstructured and includes tetrahedral elements with boundary layers on the surface of rotor, stator, and duct. Thrust and torque coefficients are computed in three different grids and are illustrated in Table 3.

As evident in Table 3, thrust coefficient in coarse mesh has the highest error. However, thrust coefficient error in medium mesh is about $0.49 \%$ which is reasonable. Therefore, the medium mesh is adopted for the numerical solution. For better illustration of the convergence trend, Figure 3 shows the thrust and torque coefficient in different grids. 
TABLE 3: Comparison of the results of hydrodynamic coefficients in different grids with experimental data [20].

\begin{tabular}{lccccccc}
\hline Type of grid & Number of elements & $K_{T}(\mathrm{NUM})$ & $K_{T}(\mathrm{EXP})$ & Percent error in $K_{T}$ & $10 K_{Q}(\mathrm{NUM})$ & $10 K_{Q}(\mathrm{EXP})$ & Percent error in $10 K_{Q}$ \\
\hline Coarse & $5,919,946$ & 0.1857 & 0.1897 & 1.98 & 0.3332 & 0.3106 & 5.57 \\
Medium & $7,816,698$ & 0.1887 & 0.1897 & 0.49 & 0.3341 & 0.3106 & 5.51 \\
Fine & $10,116,698$ & 0.189 & 0.1897 & 0.36 & 0.3345 & 0.3106 & 7.69 \\
\hline
\end{tabular}

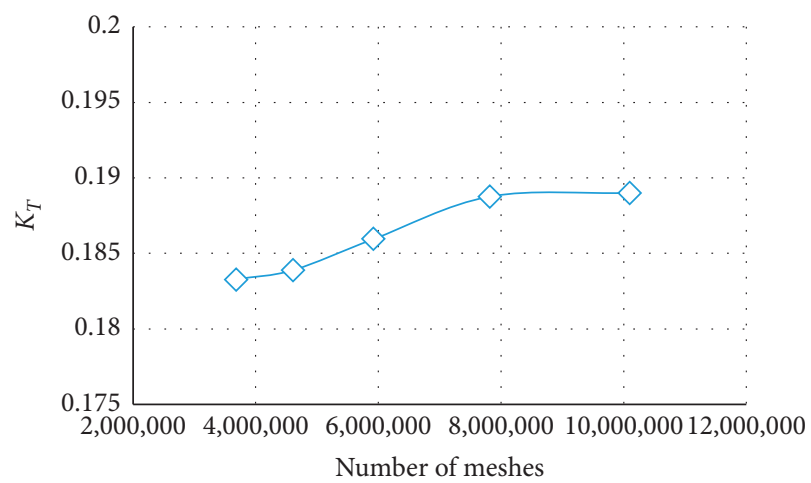

(a)

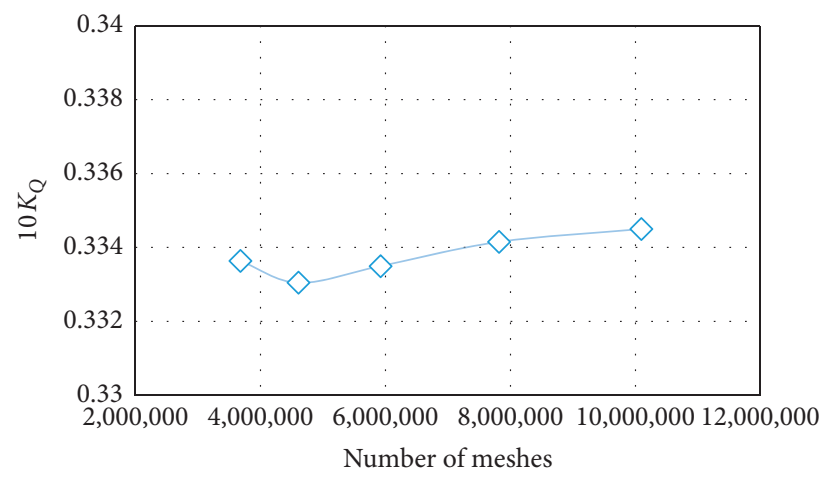

(b)

Figure 3: Thrust and torque coefficient in $J=0.6$ for different numbers of elements for propeller ka4.70, P/D = 1, and duct 19A.
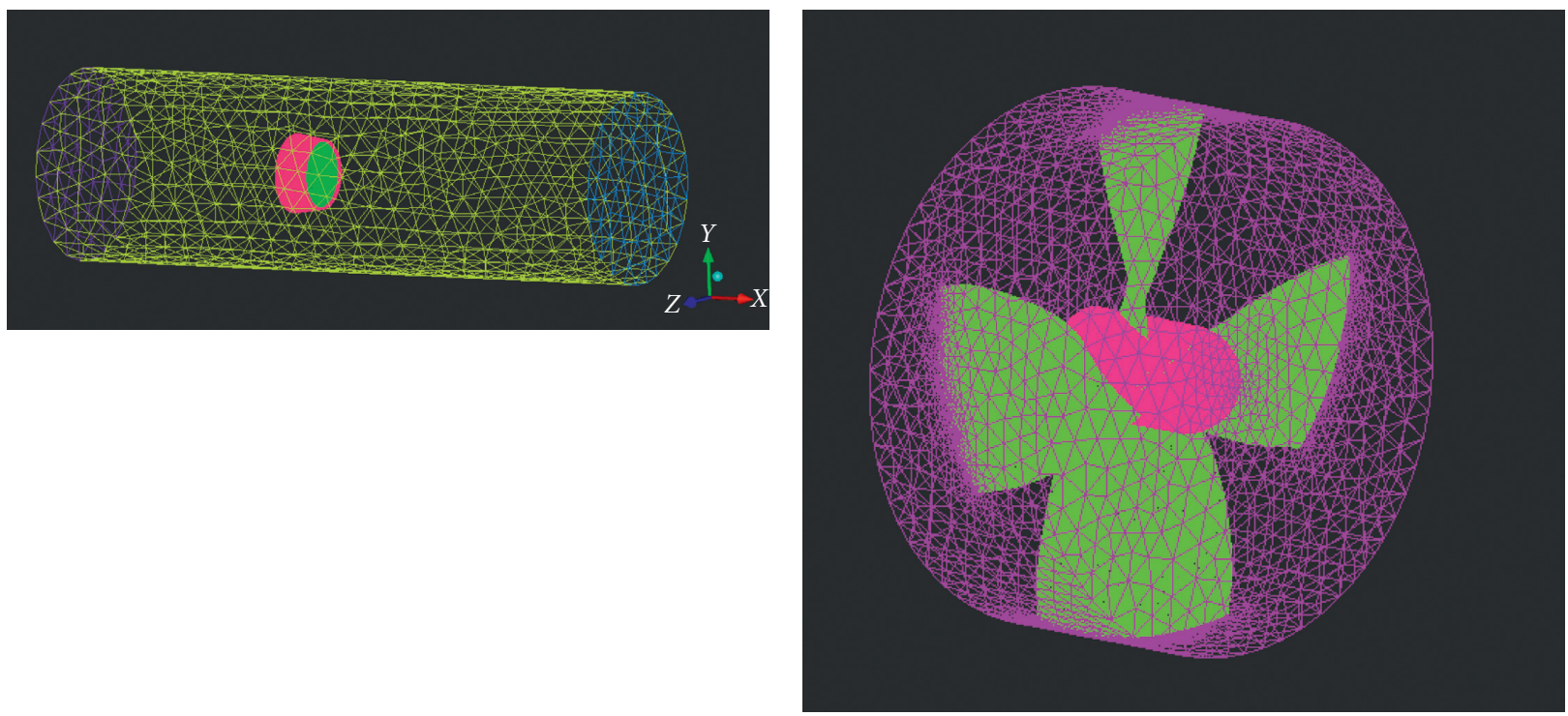

(a)

(b)

Figure 4: Mesh used in numerical solution for ka4.70, $\mathrm{P} / \mathrm{D}=1$, and duct 19A. (a) Duct domain. (b) Propeller domain.

The number of elements in the considered domain is about 8 million. Based on Figure 3, it is observed that with increase in the number of elements to more than 6 million, changes in thrust and torque coefficients become too small. Figure 4 shows the elements around the duct and the propeller.

The grid structure around the propeller is observed in Figure 4 . The number of mesh applied in propeller domain is about 2 million. According to the turbulence model, $\mathrm{Y}^{+}$on the blade of propeller and the duct is considered 30. A boundary layer is applied to the propeller and the duct. The elements created on the propeller and tip clearance are displayed in Figure 5.

As evident in Figure 5, boundary layer is applied to all surfaces of the propeller and the duct. Based on $Y^{+}$of 30 , the height of the first layer is considered as 0.00002 meters. 

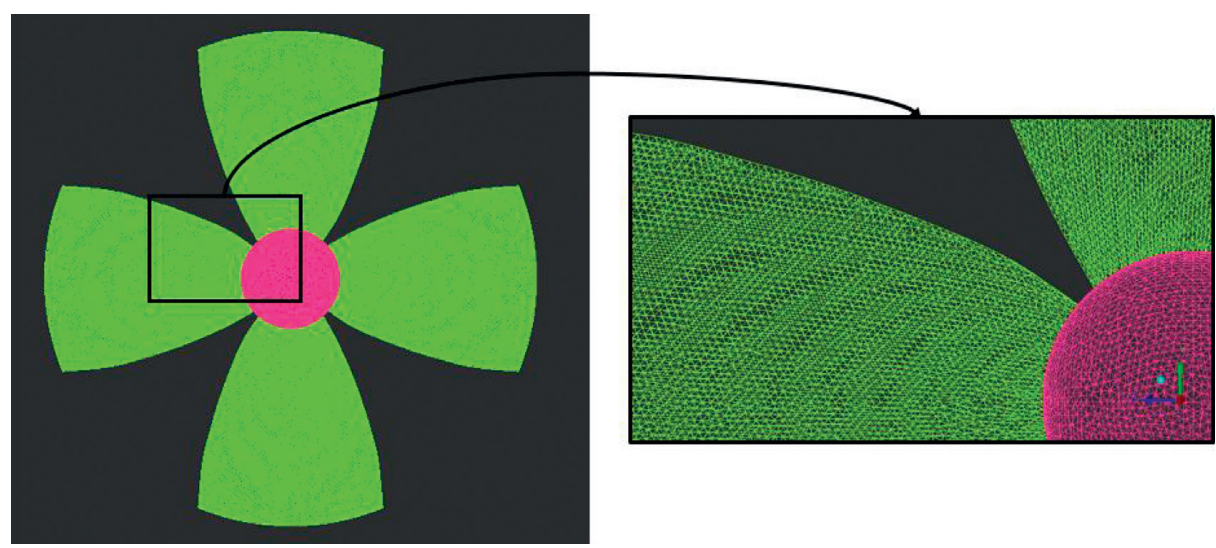

(a)
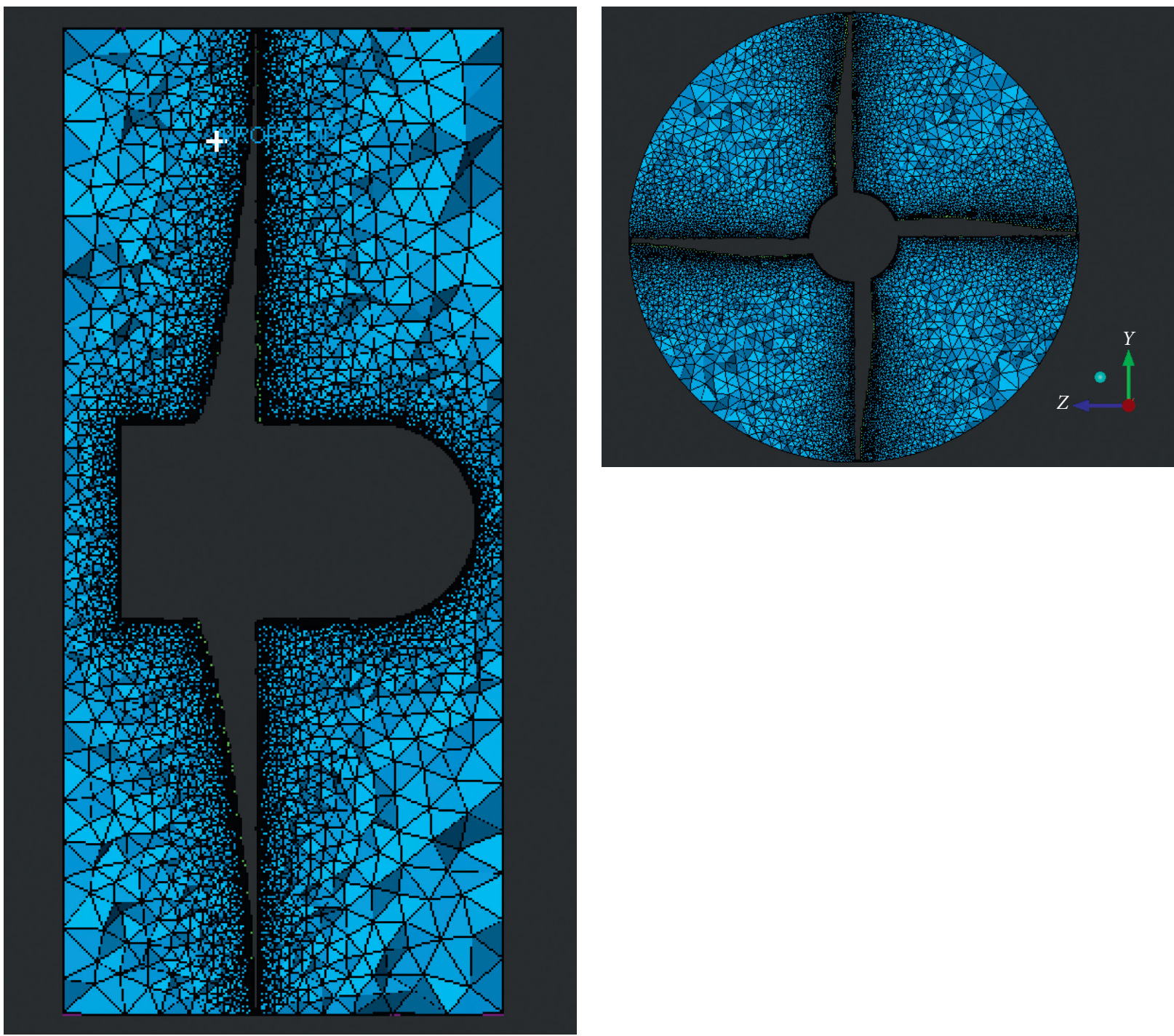

(b)

(c)

Figure 5: Continued. 


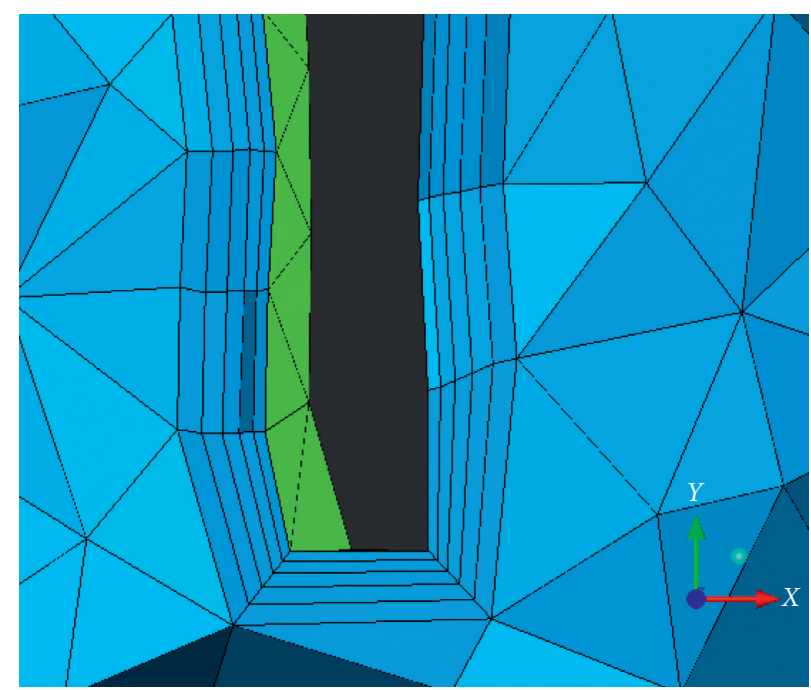

(d)

FiguRE 5: Grid structure in numerical solution for ka4.70, P/D = 1, and duct 19A. (a) Elements on the surface of the propeller and hub. (b) Side view of grids around the propeller. (c) Front view of grids around the propeller. (d) Boundary layer around propeller and inside the tip clearance.

TABLE 4: Comparison of numerical data with experimental data [21].

\begin{tabular}{lcccc}
\hline $\mathrm{J}$ & $K_{T}(\mathrm{NUM})$ & $K_{T}(\mathrm{EXP})$ & $K_{Q}(\mathrm{NUM})$ & $K_{Q}(\mathrm{EXP})$ \\
\hline 0.2 & 0.4175 & 0.4163 & 0.0433 & 0.0423 \\
0.4 & 0.3016 & 0.3111 & 0.0403 & 0.0389 \\
0.6 & 0.1857 & 0.1846 & 0.0333 & 0.0315 \\
0.8 & -0.0057 & 0.0310 & 0.0179 & 0.0193 \\
\hline
\end{tabular}

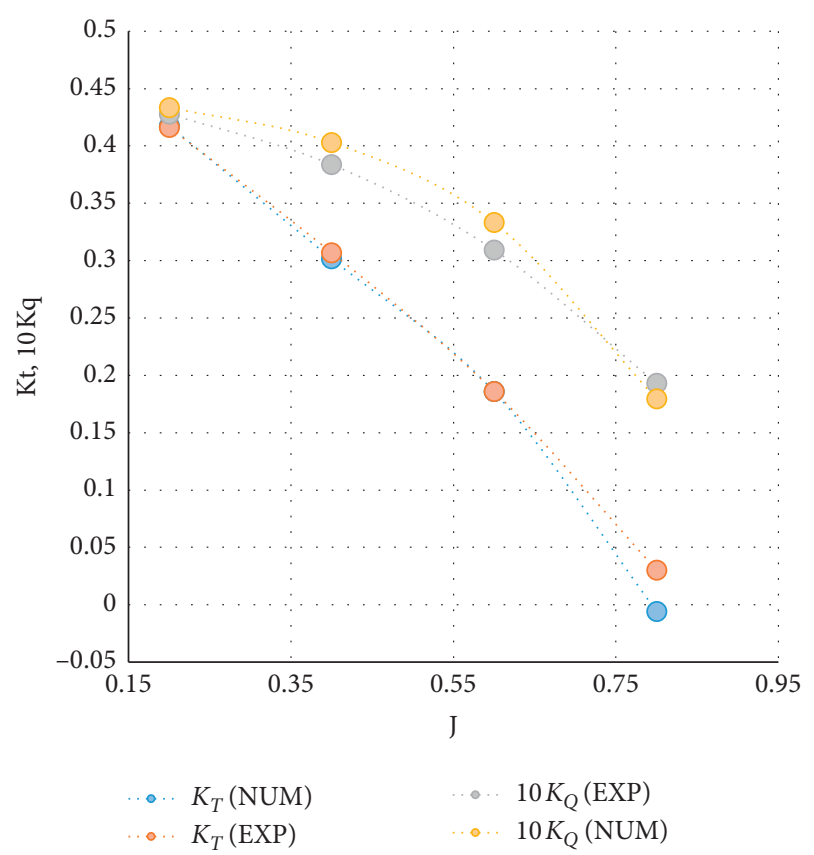

Figure 6: Comparison of numerical results of thrust and torque coefficient for propeller ka4.70 and 19A duct with experimental results [20].

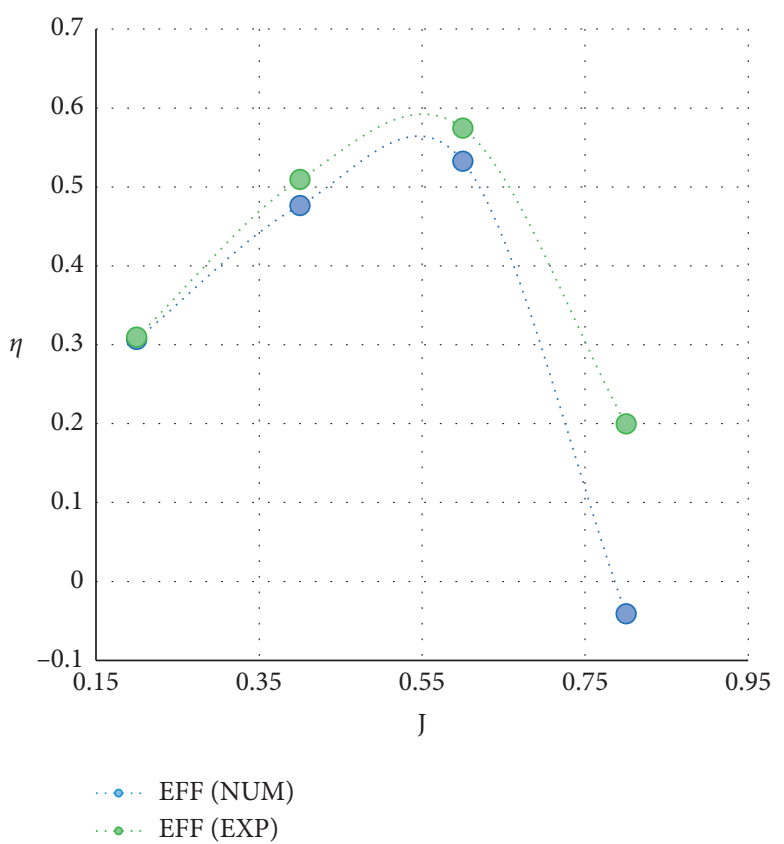

Figure 7: Comparison of numerical results of efficiency for propeller ka4.70 and 19A duct with experimental results [20].

3.3. Validation. The result of the calculations in the form of thrust coefficient and torque coefficient is displayed in Table 4 . The computed parameters are also compared with experimental data [20] in Table 4.

Based on the presented results in Table 4, it is concluded that most of the errors at various advance ratios are less than $3 \%$. The computed thrust coefficient and torque coefficient versus advance ratios are presented in Figures 6 and 7 . 


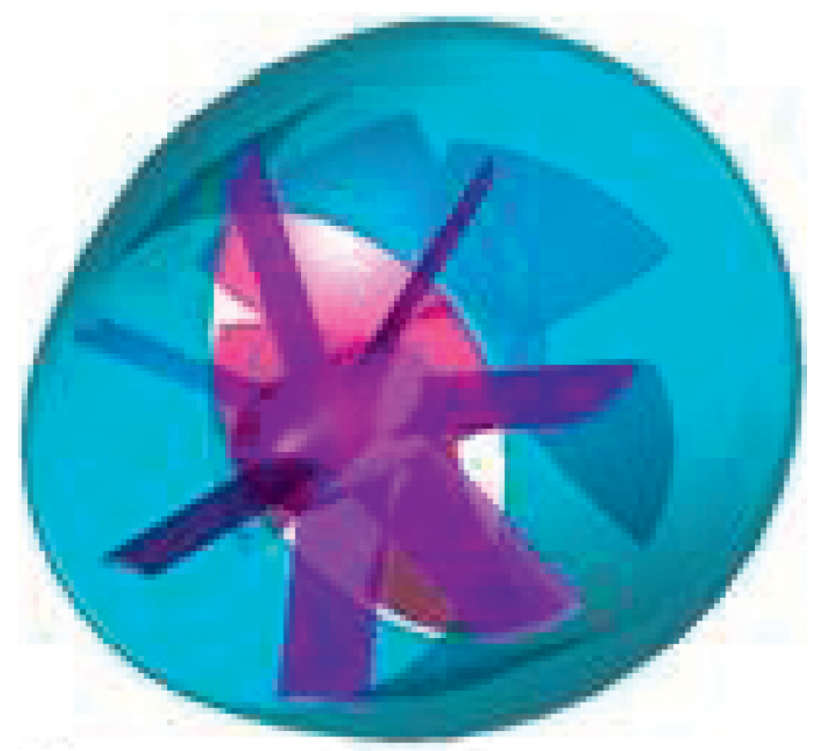

Stator

Duct

Rotor

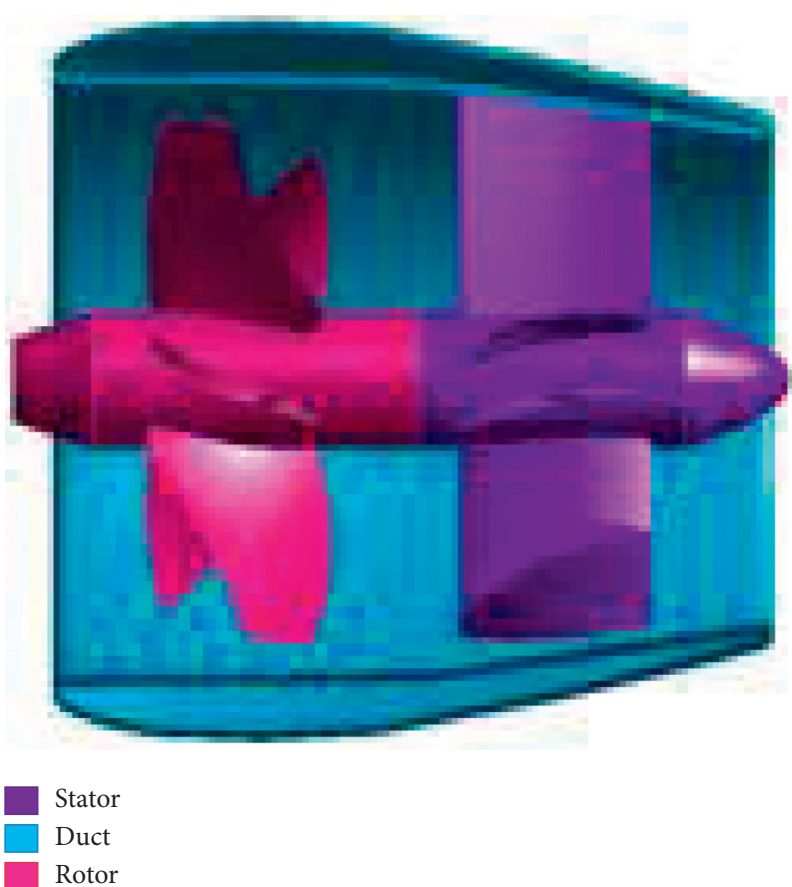

(b)

FIgURE 8: Schematics of the linear Jet system produced in prop cad: (a) isometric view and (b) side view.

As evident in Figures 6 and 7, acceptable agreement is achieved for the numerical results against experimental results in the case of thrust and torque coefficient and efficiency.

\section{Numerical Study}

As pointed out earlier, linear jet propulsion system consists of three parts and any change in its parts has a significant impact on the overall efficiency of the system. Linear jet propulsion simulation modeled in the current study is displayed in Figure 8. The rotor has 5 blades with diameter $0.2 \mathrm{~m}$, while the stator has 7 blades for generating sufficient torque to counteract the rolling torque of the propeller. The general specifications of the rotor and stator are given in Table 5. Three parts of this system are separately produced and eventually assembled. The Prop Cad software is used to produce the rotor blades of this system. Its section is selected from Kaplan series.

The stator is also one of these parts and its cross-sectional geometry has a great impact on the overall efficiency of the system. In a linear jet propulsion system, the stator is located upstream of the rotor. Therefore, the leading edge of the stator is located next to the trailing edge of the rotor (Figure 9).

There are many geometric parameters in a stator foil. In the present paper, thickness of cross section and size of the camber in the middle of the chord length are examined. In modeling this propulsion system, a decelerating duct is used to reduce cavitation around the rotor. However, the stator in front of the rotor is also used to align the flow and improve the turbulent flow out of the rotor.
TABLE 5: General information of the rotor and stator blade.

\begin{tabular}{lccc}
\hline Characteristic & $\begin{array}{c}\text { Number of } \\
\text { blades }\end{array}$ & Chord length $(\mathrm{m})$ & Diameter $(\mathrm{m})$ \\
\hline Rotor & 5 & 0.075 & 0.2 \\
Stator & 7 & 0.075 & 0.2005 \\
\hline
\end{tabular}

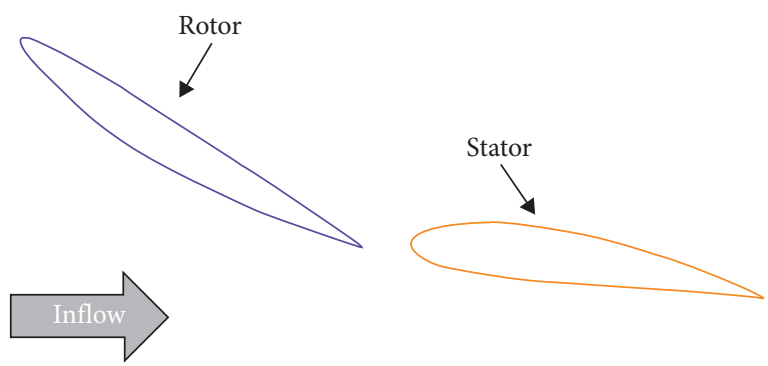

FIGURE 9: Schematics of rotor and stator cross sections in front of the flow.

In order to investigate the effects of thickness and camber size on the performance of the linear jet propulsion system, five different stator foils are selected. In the present study, NACA 0010, NACA 0015, and NACA 0020 thickness distribution (Figure 10(a)) are used to study the influence of stator blade thickness on propulsion's performance. For investigating the camber size effects, NACA 0015, NACA 3515, and NACA 6515 are used (Figure 10(b)) [21]. The camber of the stator is kept constant from hub to the tip of 
Naca0010

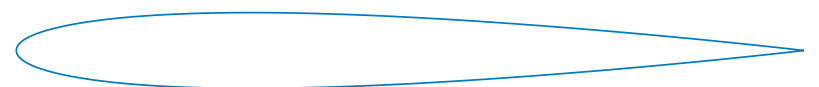

Naca0015

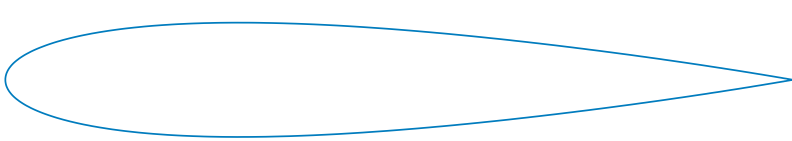

Naca0020

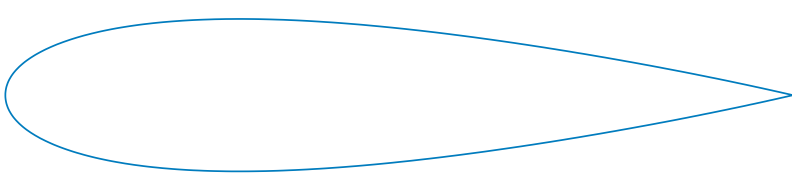

(a)
Naca0015

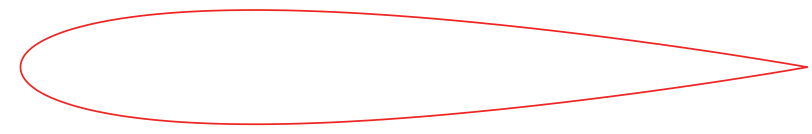

Naca3515

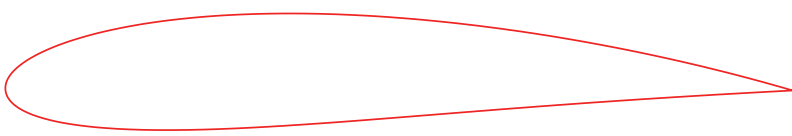

Naca6515

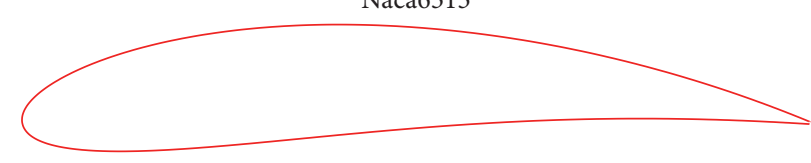

(b)

Figure 10: Types of cross sections used for stator. (a) Thickness distribution. (b) Camber distribution.

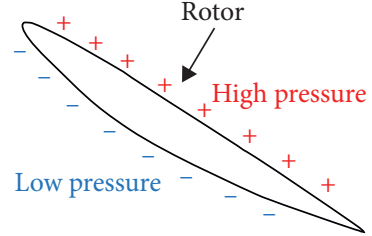

Flow

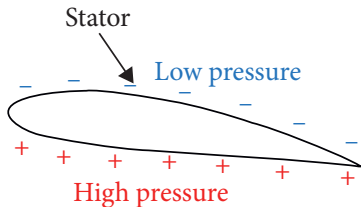

(a)

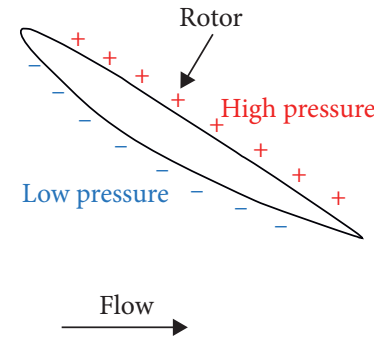

(b)

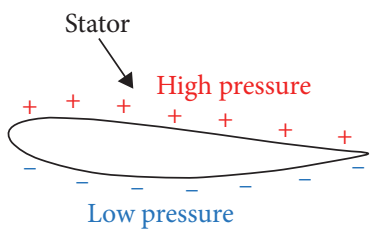

FIgURE 11: Displaying high-pressure and low-pressure surfaces around the rotor and stator at different stator locations (a, b).

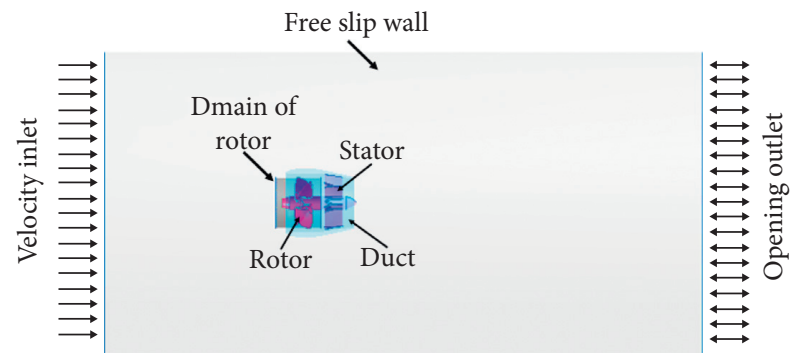

FIGURE 12: Schematics of the computational domain for the linear jet propulsion system. the postswirl stator. If the stator is correctly designed, it can also generate the thrust in positive direction (Figure 11).

The placement of the stator section is shown in two different ways, as displayed in Figure 11. In the first model (Figure 11(a)), the produced thrust in the stator is in the direction of the thrust produced in the rotor, so the total trust must be increased. However, in the second model (Figure 11(b)), the thrust produced in the stator is in the opposite direction to the rotor thrust.

The computational domain for the linear jet propulsion system, like the ducted propeller, consists of two cylinders. The computational domain and boundary conditions 
TABLE 6: Conditions of inlet flow to computational domain around the linear jet propulsion system.

\begin{tabular}{lcc}
\hline Advance ratio $(\mathrm{J})$ & Inlet velocity $(\mathrm{m} / \mathrm{s})$ & $n(\mathrm{rpm})$ \\
\hline 1.4 & 4 & 857.14 \\
1.6 & 4 & 750 \\
1.8 & 4 & 666.66 \\
2 & 4 & 600 \\
\hline
\end{tabular}

TABle 7: Thrust, torque, and efficiency for different thickness distributions in $J=1.6$.

\begin{tabular}{|c|c|c|c|c|c|c|}
\hline Thickness & Thrust of rotor $(N)$ & Thrust of stator $(N)$ & Thrust of duct $(N)$ & Total thrust $(N)$ & Torque of rotor $(N-\mathrm{m})$ & Efficiency \\
\hline NACA0010 & 176.087 & -0.659 & -67.878 & 107.548 & 11.626 & 47.113 \\
\hline NACA0015 & 176.727 & -0.800 & -62.074 & 113.852 & 11.642 & 49.806 \\
\hline NACA0020 & 177.450 & -10.811 & -56.221 & 110.416 & 11.689 & 48.105 \\
\hline
\end{tabular}

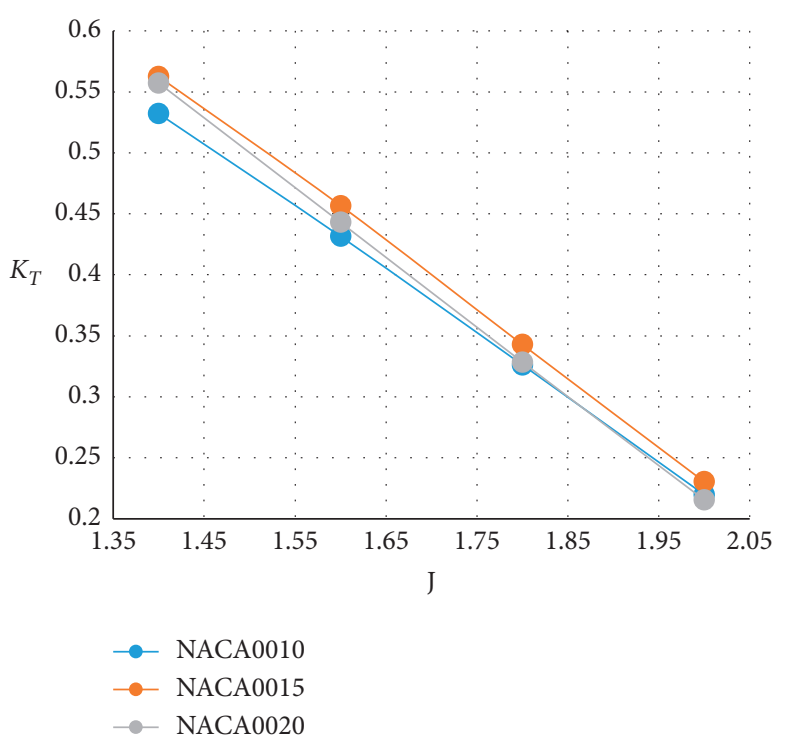

(a)

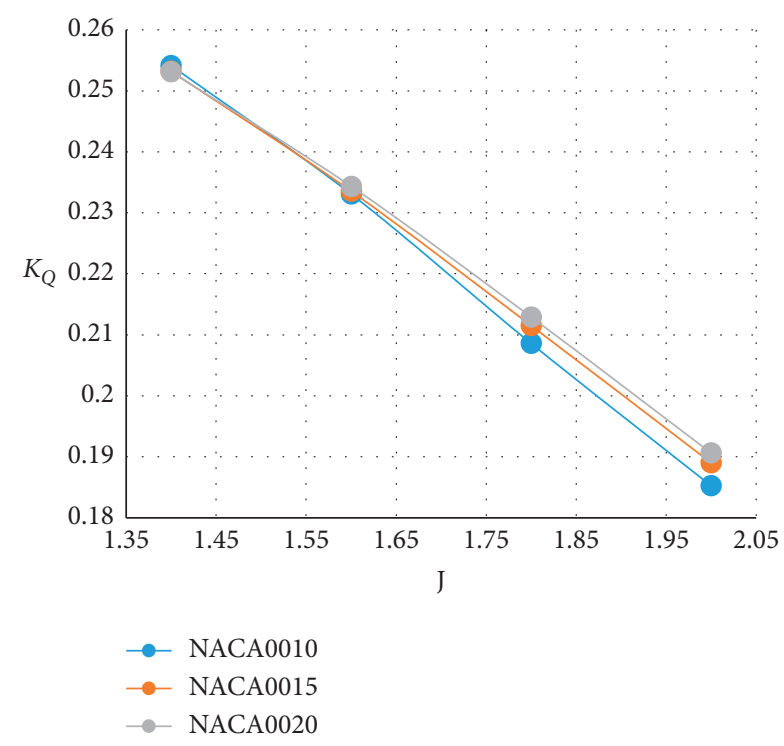

(b)

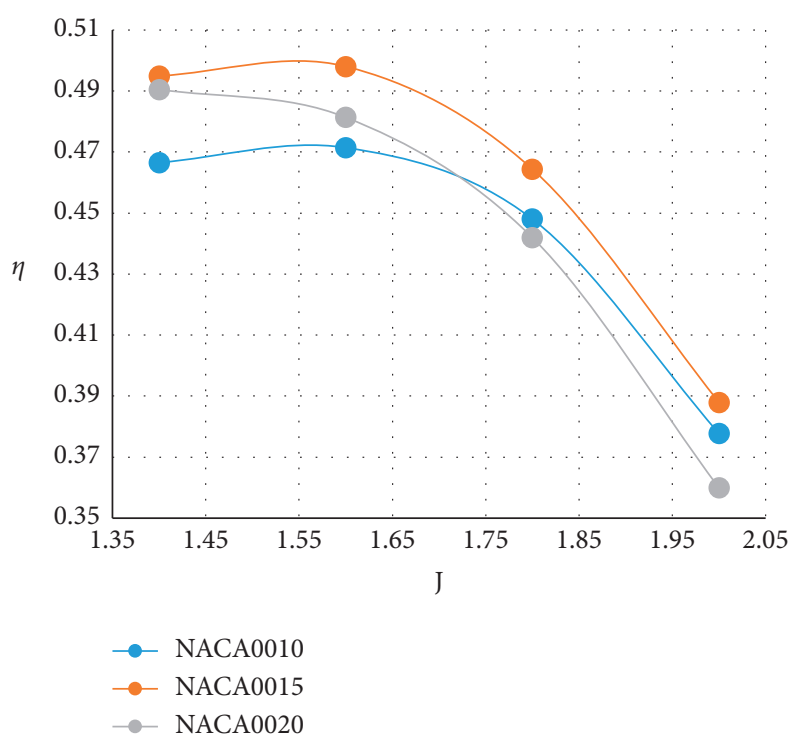

(c)

Figure 13: Thrust, torque, and efficiency coefficient for different stator thickness distribution (a, b, c). 


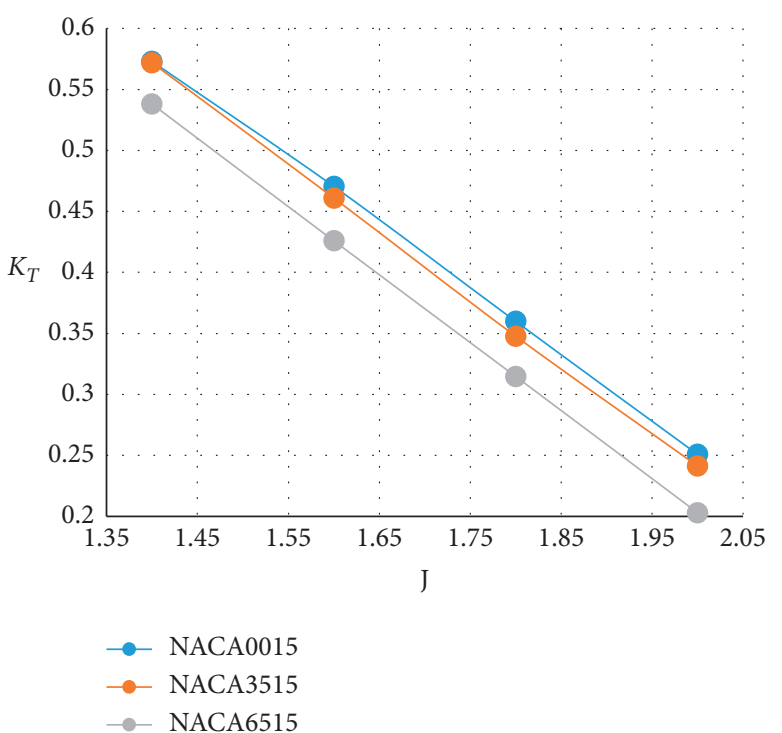

(a)

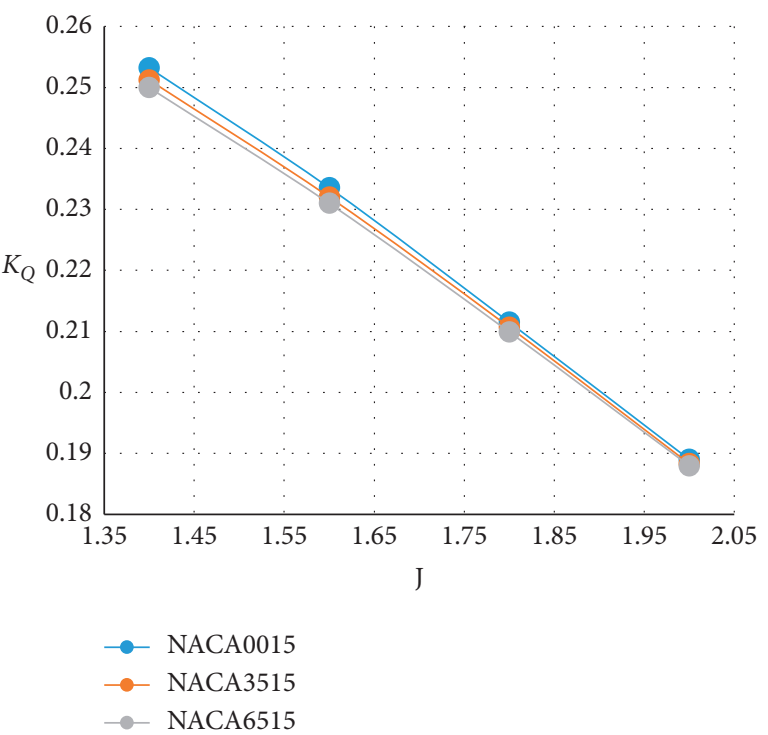

(b)

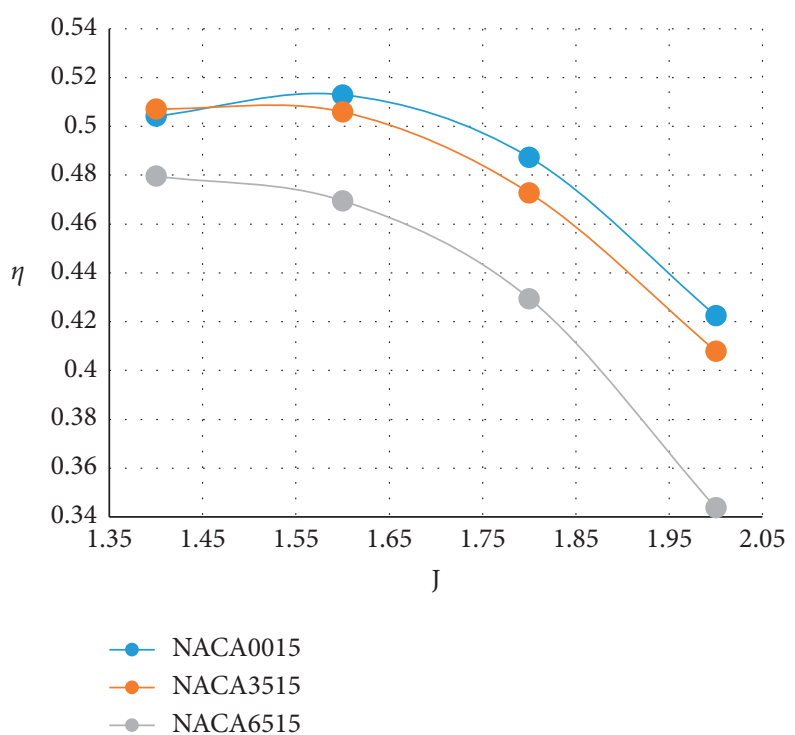

(c)

Figure 14: Thrust, torque, and efficiency coefficient for different stator camber distribution (a, b, c).

applied to the linear jet propulsion system are schematically shown in Figure 12.

Boundary conditions for the flow around linear jet in the numerical solution are applied as prescribed in Table 6. Due to the importance of pressure distribution on the stator and to reduce computational time, one of the stator blades is selected as the key stator blade and the calculations are determined based on it. In key stator blade, the size of the element on the surface of stator is $0.002 \mathrm{~m}$ and on the leading and trailing edge as well as the hub and tip, element size is $0.001 \mathrm{~m}$. Also, in other stator blades, the element size is 0.01 . The boundary layer which has a height of the first layer of about 0.00002 meters, is applied to the stator, rotor, duct, and hub.

4.1. Effect of Stator Thickness. The coefficients of thrust, torque, and efficiency for the various components of the linear jet propulsion system at the advance ratio of 1.6 are presented in Table 7.

Table 7 presents the computed thrust, torque, and efficiency as a function of different thickness distribution for the stator. The force acting on the stator with 


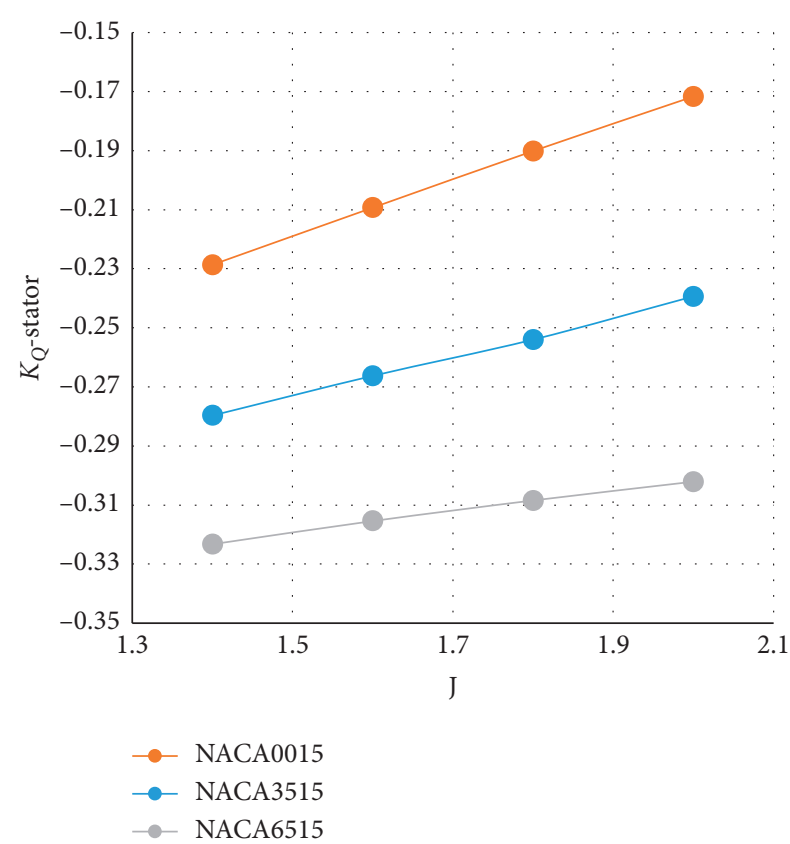

Figure 15: Torque coefficient of the stator for different stator camber distribution.

NACA0020 thickness is in the opposite direction of the thrust of the propeller. Therefore, the drag of the whole system increases if NACA0020 thickness distribution is used for the stator blade. The efficiency is calculated based on the total thrust of the propeller, duct and stator, and torque of the propeller. Maximum efficiency is achieved when the stator with thickness NACA0015 is utilized.

Subsequently, thrust, torque, and efficiency coefficients are computed at different advance ratios. Figure 13 displays the hydrodynamic coefficients for foils with different thicknesses at different advance ratios.

Thrust is expected to increase with increasing thickness. However, it is observed in Figure 13 that thrust is less in the stator with thickness NACA0020 than NACA0015. It is also evident that maximum efficiency occurs in the case of NACA0015.

4.2. Effect of the Stator Camber. Hydrodynamic coefficients of linear jet with three different stators that demonstrate the effect of camber size is displayed in Figure 14.

As evident in Figure 14, an increase in the stator cross section camber will lead to a reduction in the thrust. As a result, as the camber increases, the efficiency decreases. At a large advance ratio, this difference in efficiency is more visible. In the case of NACA3515, the efficiency is about $2 \%$ less than NACA0015 without a camber. Meanwhile, this reduction is about $20 \%$ for NACA6515.

Because of the distribution of the camber on the pitch of the stator blade, the torque caused by the stator is presented in Figure 15.

It is quite clear in Figure 15, as the camber increases, the torque caused by the stator decreases. Figure 16 shows pressure distribution on the surface of the rotor for constant turning angle from root to the tip, when NACA0015 is used as the stator's thickness distribution.

The flow separation is observed on the face side of the stator, as shown in Figure 16. Streamline diagrams of rotor and stator flow are illustrated in Figure 17.

Streamlines around the rotor are rotational due to the rotor's motion and are presented in Figures 17(a)-17(c). As expected, the rotational flow after the rotor is aligned due to the presence of the stator. However, based on Figures 17(d)$17(\mathrm{f})$, this flow alignment is not the same for different camber sizes. In the case of NACA3515, flow is so uniform that the generated vortices are smaller than in the case of NACA0015. However, in the case of NACA6515, the size of its large camber causes an additional rotation in the flow, in the opposite direction of rotor's motion. Considering the results presented in Figures 15 and 17, one may conclude that with increasing size of the camber, the torque in the opposite direction of the rotor's motion increases and consequently causes the swirling flow of the rotor to diminish.

To better express the pressure distribution, the dimensionless number of the pressure coefficients is illustrated at different distances in the length of the span in Figure 18.

Pressure coefficient along the chord length of stator is provided at different distances from the hub (different span) in Figure 18. It is observed that maximum and minimum values of the pressure coefficient occur near the leading edge of the stator. As the span length increases, the maximum and minimum values increase. Positive and negative pressure coefficients decrease with increasing foil thickness. At high-pressure side of NACA0020, pressure coefficient becomes negative after about $20 \%$ of length chord. However, at high-pressure side of NACA0015, pressure coefficients are positive in all the span lengths. Pressure coefficients of the pressure side of the stator blades remain nearly constant in the middle of the blade surface. Meanwhile, pressure coefficients of the suction side of the stator blade start getting lower, then become constant, and then gradually increase and stabilize along the chord direction at different spans. This is attributed to the presence of the cavitation which causes the pressure drop on the part of the suction side of the rotor stator. 


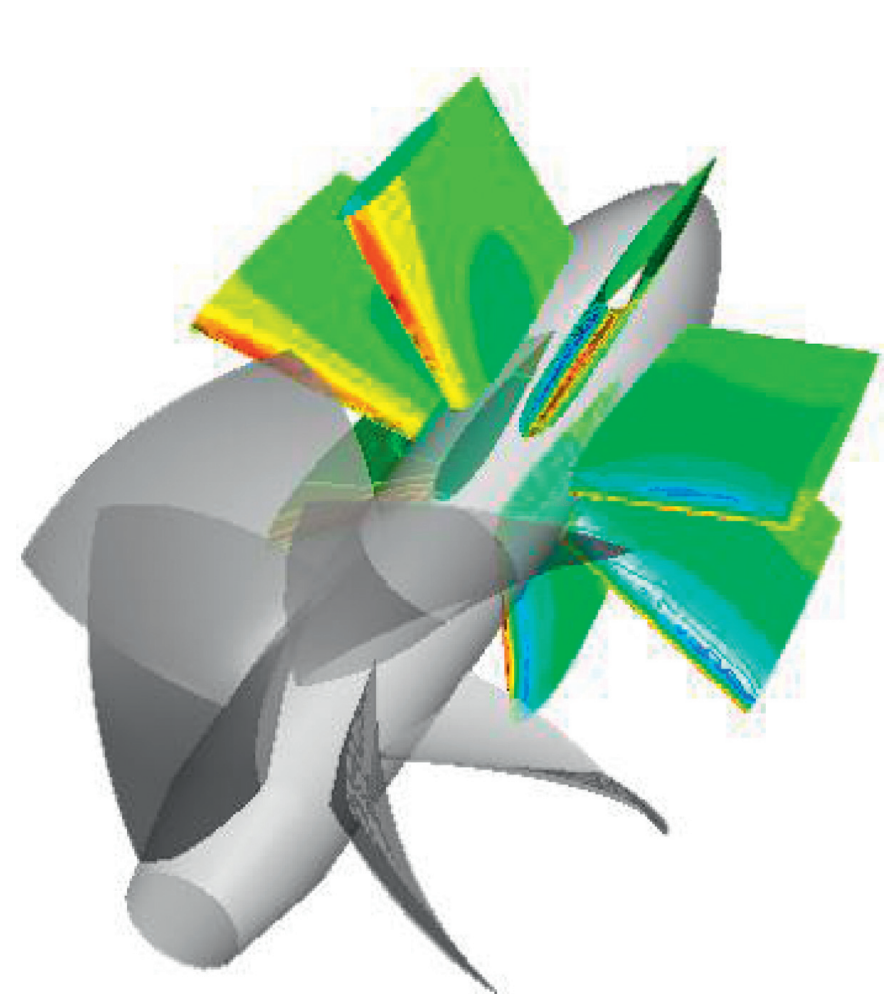

Pressure

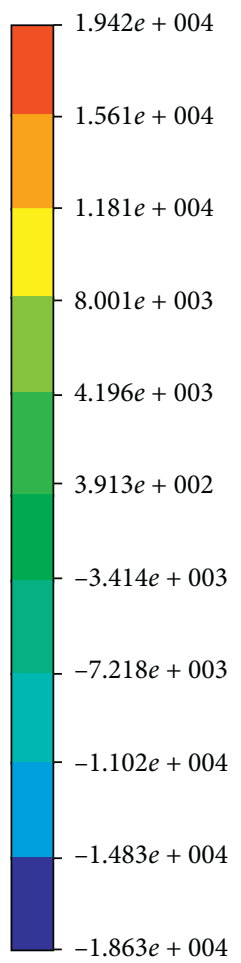

$[\mathrm{Pa}]$

Figure 16: Pressure distribution of stator at $J=1.6$.

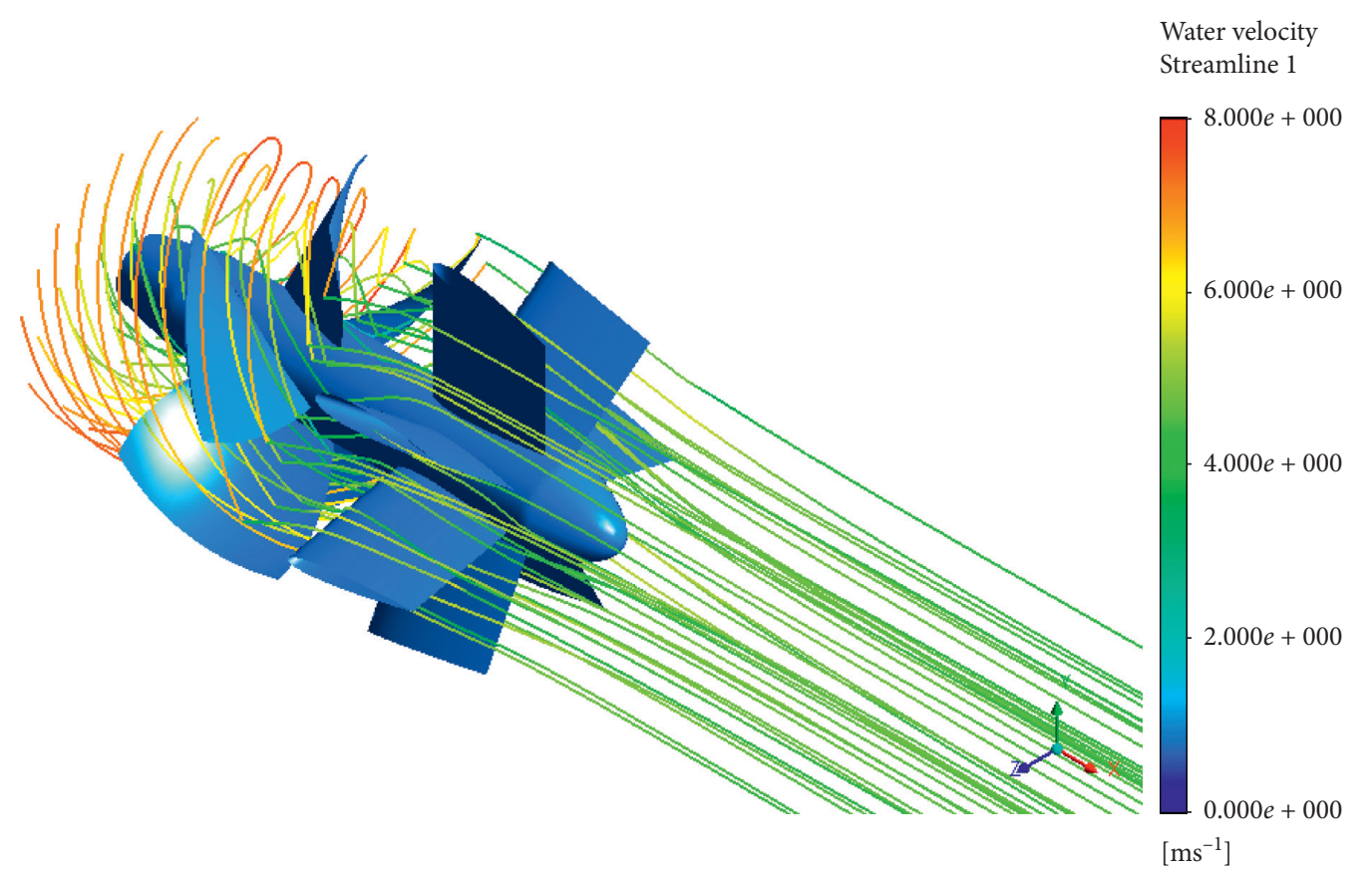

(a)

FIgURE 17: Continued. 


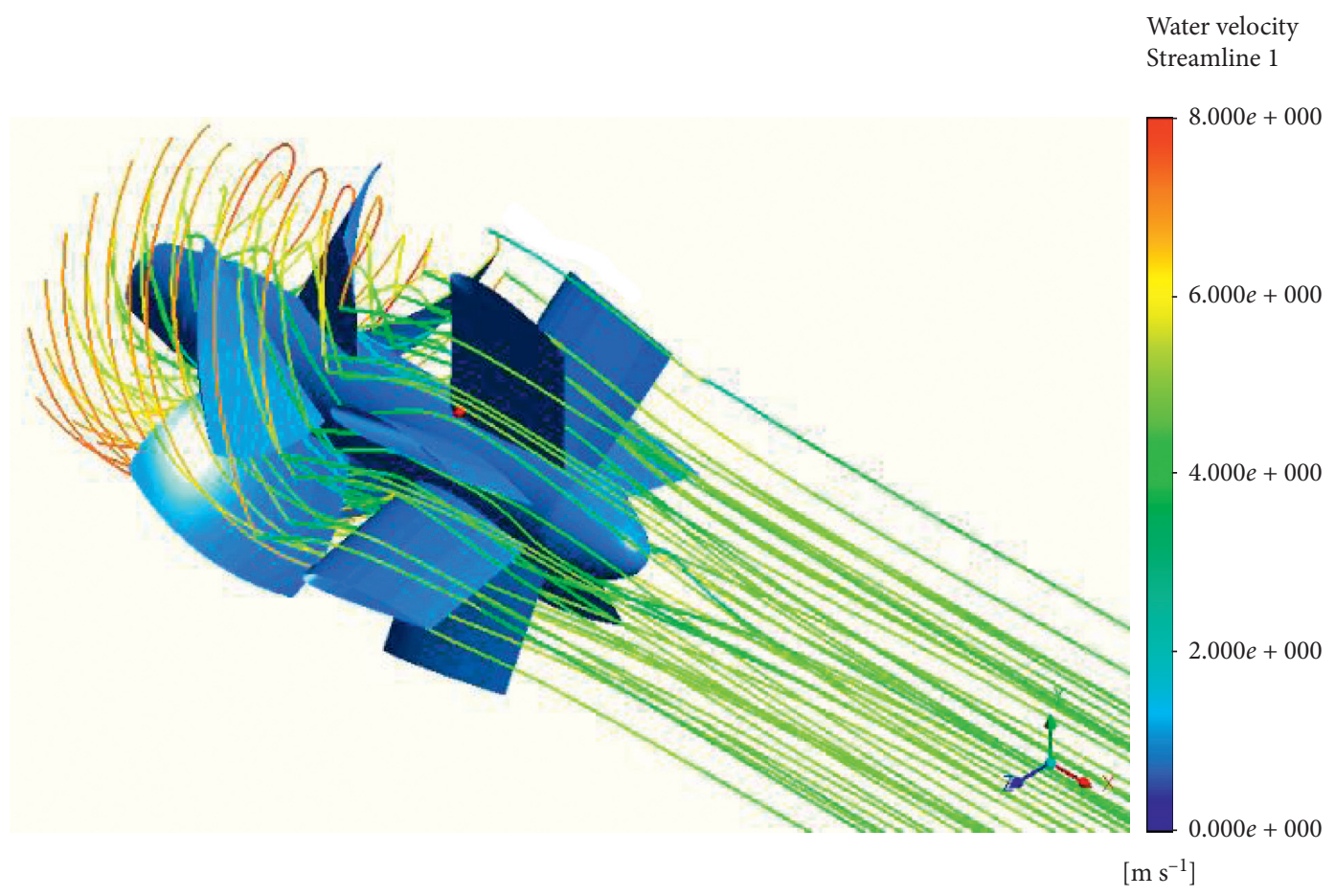

(b)

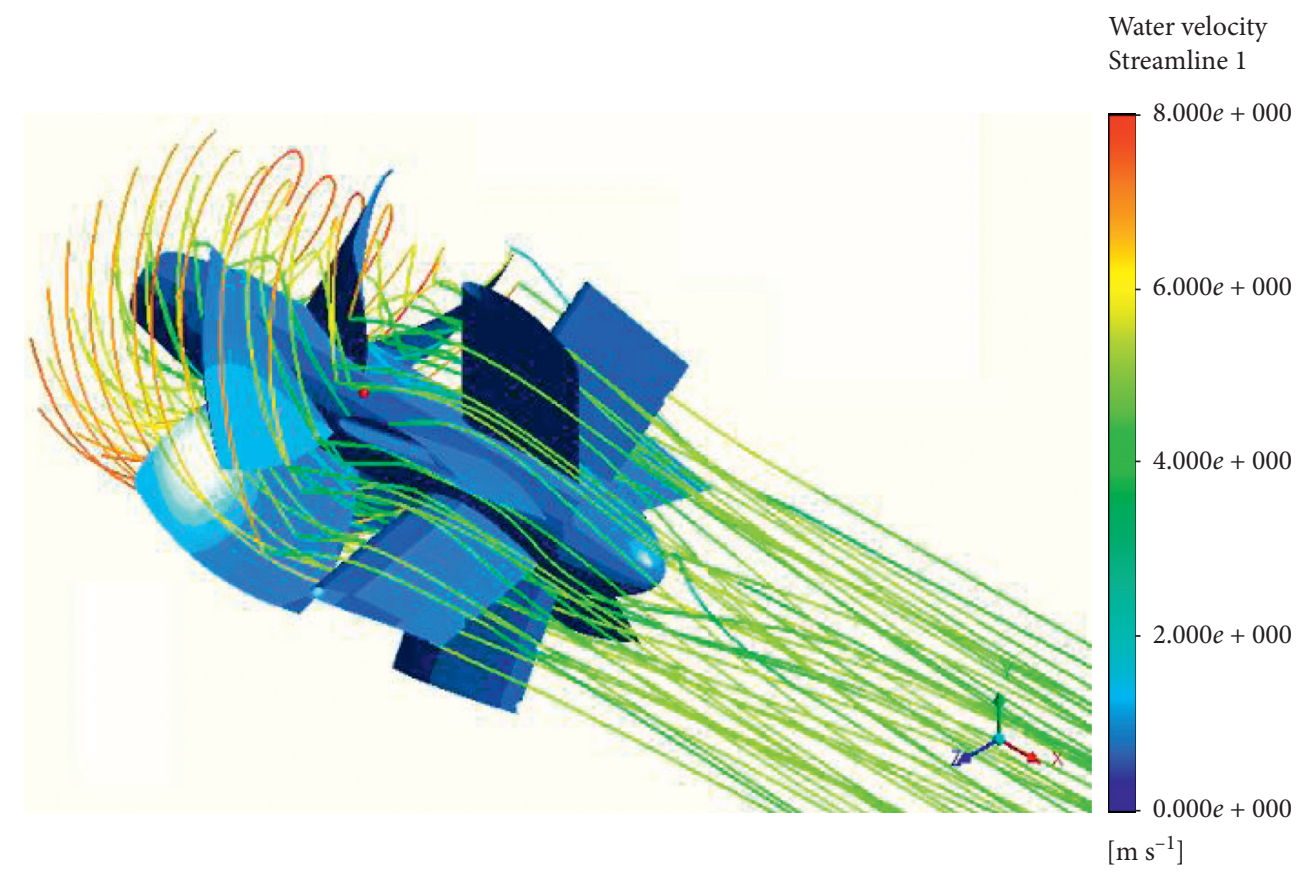

(c)

Figure 17: Continued. 


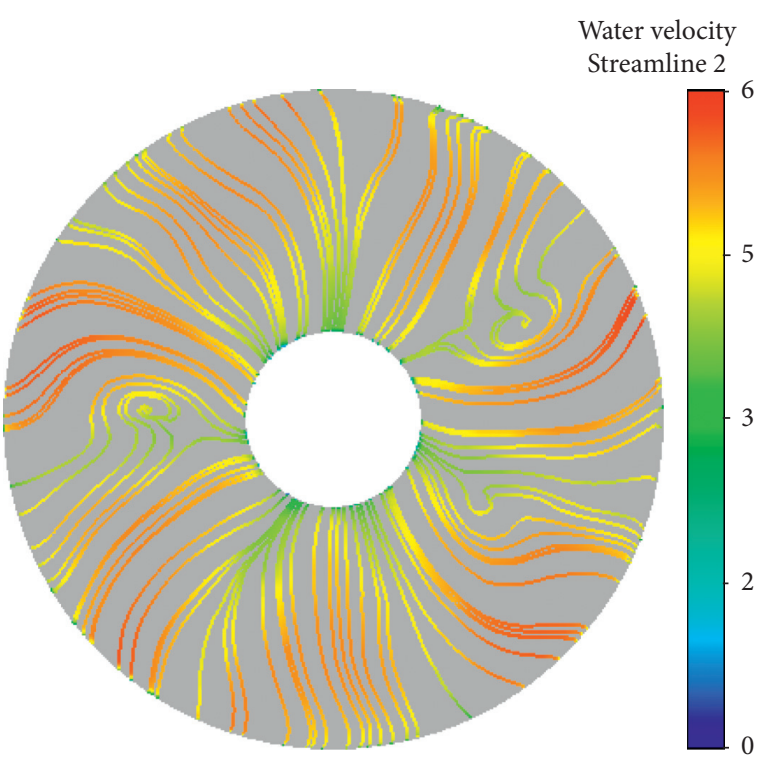

$\left[\mathrm{m} \mathrm{s}^{-1}\right]$

(d)

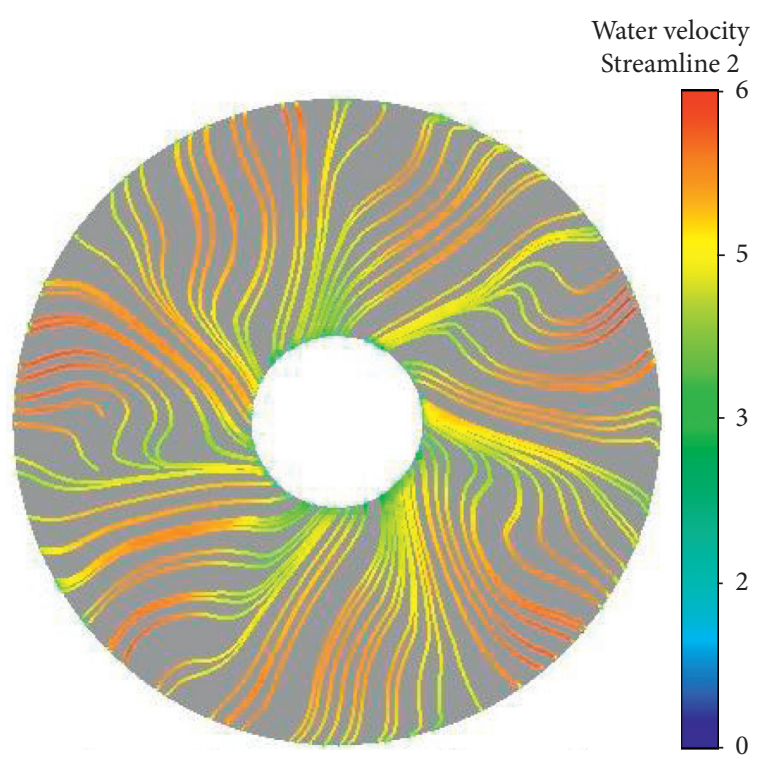

$\left[\mathrm{m} \mathrm{s}^{-1}\right.$ ]

(e)

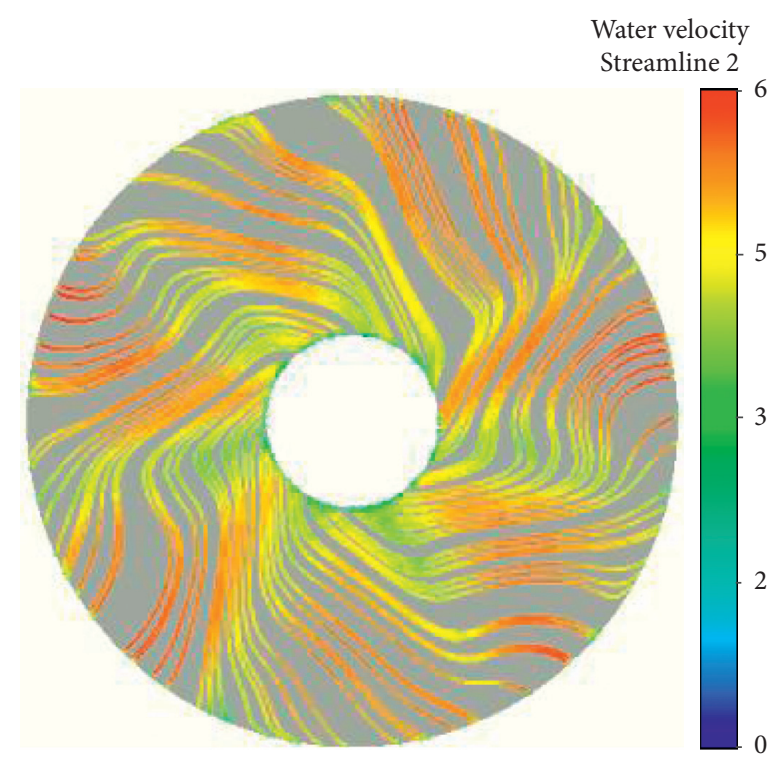

$\left[\mathrm{m} \mathrm{s}^{-1}\right.$ ]

(f)

FIGURE 17: Camber effect on streamlines around rotor and stator at $J=1.6$. (a) Streamlines of NACA0015. (b) Streamlines of NACA3515. (c) Streamlines of NACA6515. (d) 2D Streamlines of NACA0015 after stator. (e) 2D streamlines of NACA3515 after stator. (f) 2D streamlines of NACA6515 after stator. 


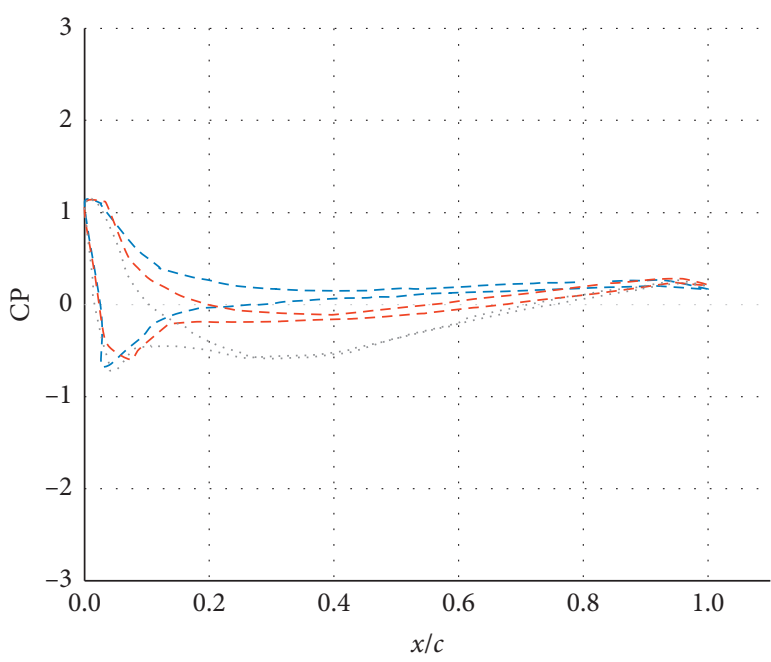

- - NACA0010

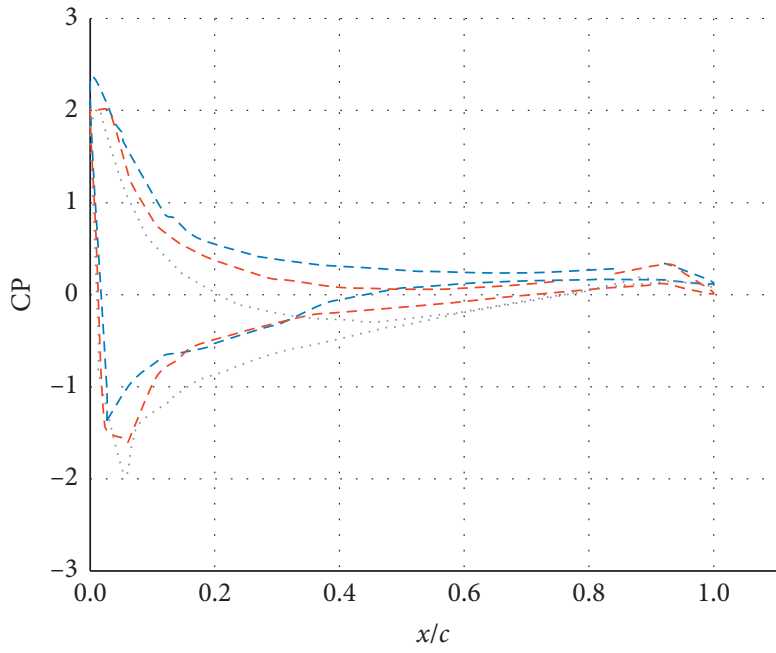

- - NACA0010

- - NACA0015

NACA0020

(a)

(b)

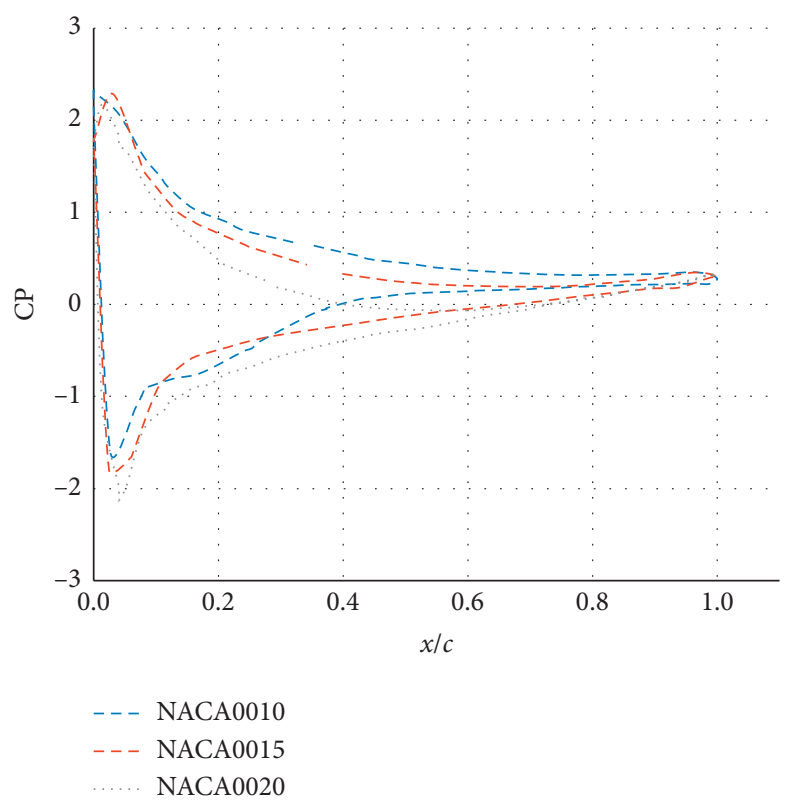

(c)

FIGURE 18: Pressure coefficient distribution in different thickness of stator at $J=1.6$. (a) Span $=0.03 \mathrm{~m}$. (b) Span $=0.06 \mathrm{~m}$. (c) Span $=0.09 \mathrm{~m}$.

Pressure distribution coefficients for different cambers of stator cross section are displayed in Figure 19.

It is observed in Figure 19(a) that pressure coefficients near the hub in different cambers are not much different. As the distance from the hub increases,
NACA6515 has a maximum and a minimum in the pressure coefficient in the middle of the length of the blade chord. However, NACA0015 exhibits a maximum and a minimum of the pressure coefficient near the leading edge. 


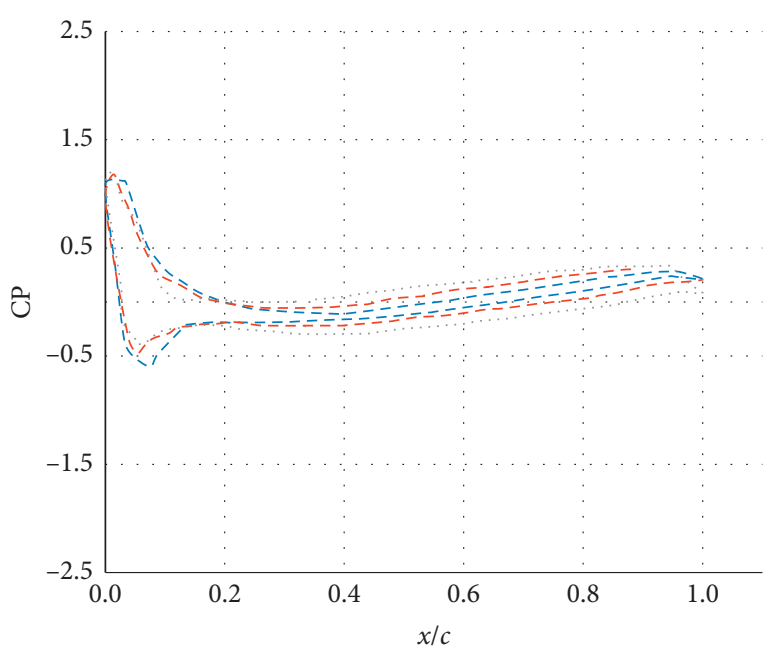

- NACA0015

- - NACA3515

NACA6515

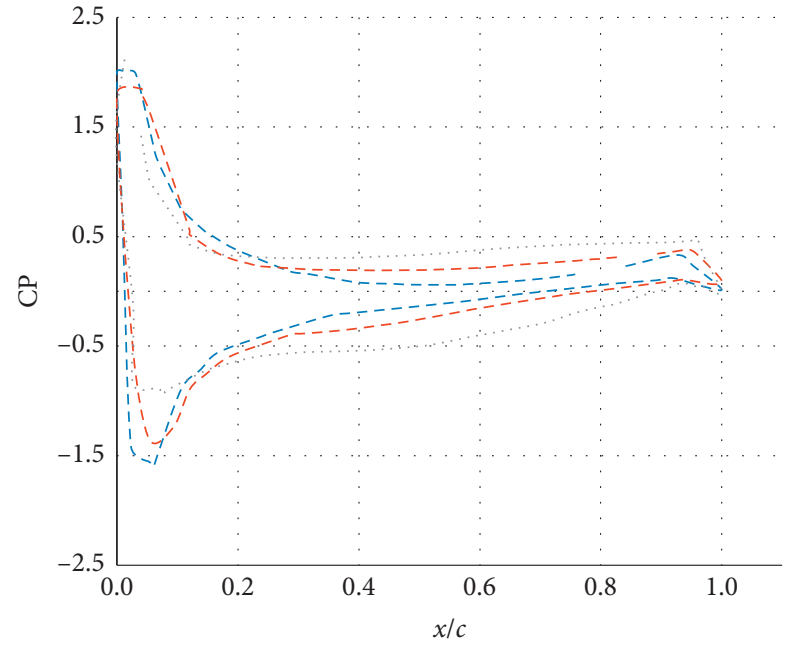

- - NACA0015

- - NACA3515

NACA6515

(a)

(b)

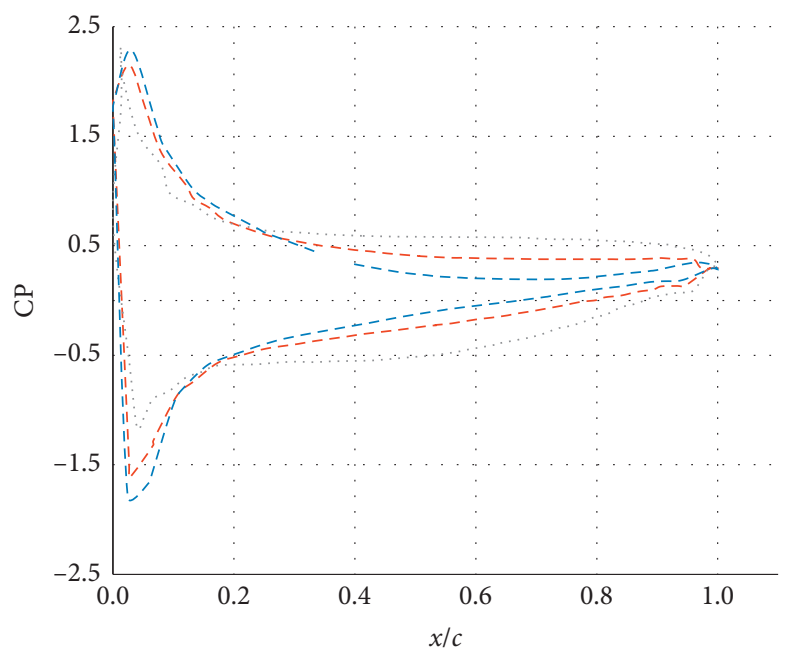

- NACA0015

- - NACA3515

NACA6515

(c)

Figure 19: Pressure coefficient distribution in different cambers of stator at $J=1.6$. (a) Span $=0.03$. (b) Span $=0.06$. (c) Span $=0.09$.

\section{Conclusion}

In this paper, a Linear Jet propulsion system with different cross sections of stator is studied to examine the influence of thickness and camber of stator clearance on its hydrodynamic performance. Ansys-CFX software is used to solve RANS unsteady equations by applying SST turbulent model. For validation purposes, hydrodynamic characteristics of a ducted propeller including the thrust coefficient, torque coefficient, and efficiency are computed at four different advance ratios. Subsequently, a geometric model is produced for the linear jet system by adding stator blades and 19A ducts. After geometry production, thrust and torque coefficients are investigated at five different cross sections in open water condition.

Based on the numerical findings, it is determined that at constant advance ratio, with increasing thickness of the stator, the efficiency increases. It is also determined that at advance ratio lower than 1.0, as the thickness of the stator increases, so does the thrust. On the other hand, at high advance ratio, the torque coefficient increases with an increase in thickness. Meanwhile, the maximum and minimum of the pressure coefficient occur near the leading edge of the stator. As the span length increases, maximum and minimum values of pressure coefficient increase for different thicknesses. It is also observed that positive and negative 
pressure coefficients decrease with an increase in foil thickness.

Future work may include a parametric study for obtaining the duct geometric characteristics such as optimal length and investigation of the propeller shape for finding the optimal parameters such as pitch.

\section{Data Availability}

The data used to support the findings of this study are available from the corresponding author upon request.

\section{Conflicts of Interest}

The authors declare that they have no conflicts of interest.

\section{References}

[1] B. Naujoks, M. Steden, S. B. Muller, and J. Hundemer, "Evolutionary optimization of ship propulsion systems," in Proceedings of the 2017 IEEE Congress on Evolutionary Computation, pp. 2809-2816, IEEE, Singapore, Asia, September 2007.

[2] Z. Q. Rao, W. Li, and C. J. Yang, "Simulation of unsteady interaction forces on a ducted propeller with pre-swirl stators," in Proceedings of the Third International Symposium on Marine Propulsors, Smp'13, vol. 13, Launceston, Tas, Australia, May 2013.

[3] M. J. Hughes and S. A. Kinnas, "An analysis method for a ducted propeller with pre-swirl stator blades," in Proceedings of the Propellers/Shafting'91 Symposium, Virginia Beach, VA, USA, September 1991.

[4] M. J. Hughes, Analysis of multi-component ducted propulsors in unsteady flow, Ph.D thesis, Department of Ocean Engineering MIT, Cambridge, MA, USA, 1993.

[5] D. Jürgens and M. Bohm, Linear-Jet: A Propulsion System for Fast Ships, PRADS, The Hague, The Netherlands, 1998.

[6] S. Ivanell, "Hydrodynamic simulation of a torpedo with pump jet propulsion system," Master thesis, Royal Institute of Technology, Stockholm, Sweden, 2001.

[7] W.-G. Park, Y.-R. Jung, and C.-K. Kim, "Numerical flow analysis of single-stage ducted marine propulsor," Ocean Engineering, vol. 32, no. 10, pp. 1260-1277, 2005.

[8] D. Jürgens and H.-J. Heinke, "Untersuchung tief-getauchter Waterjets," in Proceedings of the Paper Presented at the Annual Meeting of STG held at Hamburg, Berlin, Germany, November 2006.

[9] B. Naujoks, M. Steden, S. B. Müller, J. Hundemer, and M. Abdel-Maksoud, Optimisation of a Linear Jet Propeller Blade Evolutionary Methods for Design, Optimization and Control, CIMNE, Barcelona, Spain, 2007.

[10] S. E. Kim, "Multiphase CFD simulation of turbulent cavitating flows in and around marine propulsors," in Proceedings of the Open Source CFD International Conference, Barcelona, Spain, November 2009.

[11] C. H. Suryanarayana, B. Satyanarayana, K. Ramji, and A. Saiju, "Experimental evaluation of pumpjet propulsor for an axisymmetric body in wind tunnel," International Journal of Naval Architecture and Ocean Engineering, vol. 2, no. 1, 2010.

[12] C. H. Suryanarayana, B. Satyanarayana, K. Ramji, and A. Saiju, "Performance evaluation of an underwater body and pumpjet by model testing in cavitation tunnel," International
Journal of Naval Architecture and Ocean Engineering, vol. 2, no. 2, pp. 57-67, 2010.

[13] K. Sorbello, The Voith Linear Jet: Combining the Best of Two Options, Gcaptain, Los Osos, CA, USA, 2012.

[14] G. Pan and L. Lu, "Numerical investigation of a pumpjet propulsor based on CFD," International Journal of Control and Automation, vol. 8, no. 11, pp. 225-234, 2015.

[15] G. Pan, L. Lu, and P. K. Sahoo, "Numerical simulation of unsteady cavitating flows of pump jet propulsor," Ships and Offshore Structures, vol. 11, no. 1, pp. 64-74, 2016.

[16] L. Lu, G. Pan, and P. K. Sahoo, "CFD prediction and simulation of a pumpjet propulsor," International Journal of Naval Architecture and Ocean Engineering, vol. 8, no. 1, pp. 110-116, 2016.

[17] M. Motallebi-Nejad, M. Bakhtiari, H. Ghassemi, and M. Fadavie, "Numerical analysis of ducted propeller and pumpjet propulsion system using periodic computational domain," Journal of Marine Science and Technology, vol. 22, no. 3, pp. 559-573, 2017.

[18] A. T. Shirazi, M. R. Nazari, and M. D. Manshadi, "Numerical and experimental investigation of the fluid flow on a full-scale pump jet thruster," Ocean Engineering, vol. 182, pp. 527-539, 2019.

[19] H. Li, G. Pan, and Q. Huang, "Transient analysis of the fluid flow on a pumpjet propulsor," Ocean Engineering, vol. 191, Article ID 106520, 2019.

[20] M. W. C. Oosterveld, "Ducted propeller characteristics," in Proceedings of the RINA Symposium on Ducted Propellers, Teddington, England, June 1973.

[21] S. Pawar, S. Brizzolara, W. L. Neu, and D. J. Stilwell, “Design of ducted propulsors for towing autonomous underwater vehicles," in Proceedings of the OCEANS 2018 MTS/IEEE Charleston, IEEE, Charleston, South CA, USA, pp. 1-8, October 2018. 